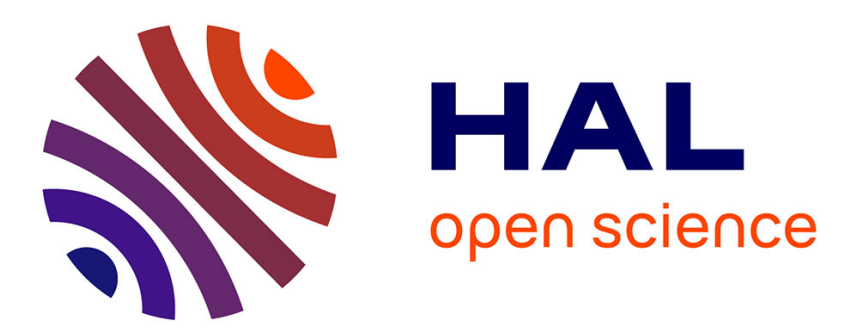

\title{
Membrane Organization and Physical Regulation of Lymphocyte Antigen Receptors: A Biophysicist's Perspective
}

Laurent Limozin, Pierre-Henri Puech

\section{- To cite this version:}

Laurent Limozin, Pierre-Henri Puech. Membrane Organization and Physical Regulation of Lymphocyte Antigen Receptors: A Biophysicist's Perspective. Journal of Membrane Biology, 2019, 252 (4-5), pp.397-412. 10.1007/s00232-019-00085-2 . hal-02401221

\section{HAL Id: hal-02401221 \\ https://hal.science/hal-02401221}

Submitted on 9 Dec 2019

HAL is a multi-disciplinary open access archive for the deposit and dissemination of scientific research documents, whether they are published or not. The documents may come from teaching and research institutions in France or abroad, or from public or private research centers.
L'archive ouverte pluridisciplinaire HAL, est destinée au dépôt et à la diffusion de documents scientifiques de niveau recherche, publiés ou non, émanant des établissements d'enseignement et de recherche français ou étrangers, des laboratoires publics ou privés. 


\title{
Membrane organization and physical regulation of lymphocyte antigen receptors: a biophysicist's perspective
}

\author{
Laurent Limozin* and Pierre-Henri Puech \\ Laboratoire Adhesion and Inflammation Aix-Marseille University Inserm CNRS \\ Luminy, Marseille, France \\ * : corresponding author: laurent.limozin@inserm.fr
}

\begin{abstract}
Receptors at the membrane of immune cells are the central players of innate and adaptative immunity, providing effective defence mechanisms against pathogens or cancer cells. Their function is intimately linked to their position at and within the membrane which provides accessibility, mobility as well as membrane proximal cytoskeleton anchoring, all of these elements playing important roles in the final function and links to cellular actions. Understanding how immune cells integrate the specific signals received at their membrane to take a decision remains an immense challenge and a very active field of fundamental and applied research. Recent progress in imaging and micromanipulation techniques have led to an unprecedented refinement in the description of molecular structures and supramolecular assemblies at the immune cell membrane, and provided a glimpse into their dynamics and regulation by force. Several key elements have been scrutinized such as the roles of geometry (relative sizes of molecules), lateral organisation, motion in the membrane of the receptors, but also physical cues such as forces, mediated by cellular substrates of different rigidities or applied by the cell itself, in conjunction with its partner cell. We review here these recent discoveries associated with a description of the biophysical methods used. While a conclusive picture integrating all of these components is still lacking, mainly due to the implication of diverse and different mechanisms and spatiotemporal scales involved, the amount of quantitative data available opens the way for physical modelling and numerical simulations and new avenues for experimental research.
\end{abstract}

\author{
ABBREVIATIONS \\ AFM: Atomic Force Microscopy \\ APC: Antigen Presenting Cell \\ BCR: B Cell Receptor \\ BFP: Bio-membrane Force Probe \\ CAR: Chimeric Antigen Receptor \\ CDR: Complementary Determining Regions \\ FcR: Constant Fragment Receptor \\ FCS: Fluorescence Correlation Microscopy \\ FRAP: Fluorescence Recovery After Photobleaching \\ FRET: Förster Resonance Energy Transfer \\ ICAM: Inter Cellular Adhesion Molecule \\ Ig: Immunoglobulin \\ ITAM: Immuno-receptor Tyrosine-based Activation Motifs \\ ITIM: Immuno-receptor Tyrosine-based Inhibition Motifs \\ LFA-1: Lymphocyte Function-associated Antigen 1 \\ LFC: Laminar Flow Chamber \\ NK: Natural Killer \\ pMHC: peptide Major Histocompatibility Complex \\ RICM: Reflection Interference Contrast Microscopy \\ SIM: Structured Illumination Microscopy \\ SMLM: Single Molecule Localisation Microscopy \\ TCR: T Cell Receptor \\ TFM: Traction Force Microscopy \\ TIRF: Total Internal Reflection Fluorescence
}




\section{INTRODUCTION}

\section{Receptors in immunity}

Receptors at the membrane of immune cells are the main specific molecular actors of innate and adaptative immunity, providing the defence of our organism against pathogens or cancer cells. Their structure, localisation, interactions and collective organisation in the membrane determine their functional behaviour. In a nutshell, these receptors are in charge of recognising a given class or a specific species of pathogenic antigens in order for a cellular immune response to start, which will include the destruction of the pathogen. Specificity is crucial for avoiding autoimmunity i.e. an immune response against self-antigens. Additionally, sensitivity and speed in the recognition are required because a pathogen should be detected as early as possible among an immense variety of non agonist molecules (Krogsgaard and Davis 2005). Despite the number of genetic and biochemical data gathered on these aspects, how this is achieved remains to be fully understood, in particular by linking the different scales in space and time. In this context, complementary experimental approaches and concepts should be considered. Thus integrating biochemical, structural and biophysical cues has become central to decipher immune cell function (Malissen and Bongrand 2015; Hivroz and Saitakis 2015).

\section{Receptors self-organisation and mechanical regulation}

The study of mechano-biological processes has exploded in the recent years, reaching also the field of immunology, thanks to progresses in imaging and micro-manipulations of molecules and cells, allowing mechanical measurements and perturbations of individual cell components and living cells. Indeed, immunological cells and receptors present various original features making them ideal model systems for mechano-biological approaches. Immune cells are fundamentally circulating cells which are not strictly part of a tissue, justifying per se in vitro studies of individual cells. They are soft and easily deformable due to rapid cytoskeleton reorganisations (Burkhardt 2008). They are often motile with labile adhesion and signalling platform due to rapid reorganisation of the receptors at and below the membrane (Dustin and Groves 2012). How these mechanical and chemical aspects are integrated to achieve immune cell function is still largely unknown. At the molecular level, antigenic receptors have the capability of recognising a huge diversity of molecules due to combinatorial variations in recognising motifs. Understanding how receptors, together with coreceptors and adapter / signalling molecules, self-organise to induce specific recognition and controlled immune response remains a big challenge (He and Bongrand 2012). For example, controlled multivalency as for antibodies is an important feature of immune receptors which still lacks a precise definition and a quantitative understanding. Finally, adaptative immunity is based on the production of new receptor variants by an accelerated evolutionary process; it provides thus a rich system to explore the role of mechanical dimension in molecular evolution.

\section{Outline}

In this review, we will focus on how biophysical parameters, in particular forces, are playing a role in the organisation and function of immune receptors in the cellular membrane. A first important aspect to emphasise is that recognition often occurs at the interface between two cells, the immune cell and the antigen presenting cell, thus imposing important geometrical and physical constraints to the processes. Molecules are confined in crowded, 2D environment and subjected to lateral or tangential forces with respect to the membrane they are embedded in. For example, receptors of $\mathrm{B}$ and $\mathrm{T}$ lymphocytes recognise their antigen when presented by other cells. Cytotoxic $\mathrm{T}$ cells are scanning the surface of encountered cells, looking for information about their state, by palpating the surface and circulating around the target cell. Here, we will detail the limitations of traditional biochemistry derived techniques in this context and present recently developed biophysical techniques aimed at reproducing better the physiological situation, as well as extracting new important parameters, such as resistance and sensitivity to force or mechanical characteristics of cells, largely ignored until recently.

\section{STRUCTURE AND FUNCTION OF ANTIGEN RECEPTORS}

\section{Different types of receptors (Figure 1)}

An important diversity of immune receptors are present at the surface of the various immune cells types and play a central role in their identification, communication and function. We will focus mainly on the receptors present at the surface of lymphoid cells like B and T lymphocytes, as well as Fc Receptors of natural killer (NK) cells. These cells have the capacity to form immune synapses, a close and highly structured contact with partner cells, the term coined by analogy with the neuronal synapse (Grakoui 1999). B cell receptors (BCRs) are in charge of recognising extracellular antigens and are precursor of antibodies. T cell receptors (TCRs) are in charge of recognising intracellular antigens, in the form of short peptide fragments ( 10 amino acids) carried by MHC (Major Histocompatibility Complex) present at the surface of nucleated cells (Murphy 2016). Two subtypes exist, one is present on nucleated cells (MHCI), the other only on professional Antigen Presenting Cells (APCs) such as dendritic cells and macrophages (MHCII). Natural Killer (NK) cells possess a variety of surface receptors which can be targeted for cancer immunotherapy (Chiossone 2018). Among them, Fc receptors, present also on many immune cell types, are in charge of binding the constant fragment of the antibodies; this mechanism permit for innate immune cells to exploit the unique specificity of antigen receptors 
characteristics of adaptative immune cells via antibodies. While NK cells may be considered as lymphocytes of the innate immunity, their recently discovered ability to retain immunological memory (Adams 2016, Boudreau 2018), confer them an additional trait of adaptative immunity (Vivier 2011). Adhesion receptors, some of them specific of immune cells, are part of the large families of integrins, selectins and immunoglobulins. Some other important immune receptors, which bind soluble ligands, will not be considered in this review and include: cytokine and chemokine receptors (some G-protein coupled receptors) and Toll-like receptors at the surface of innate immune cells.

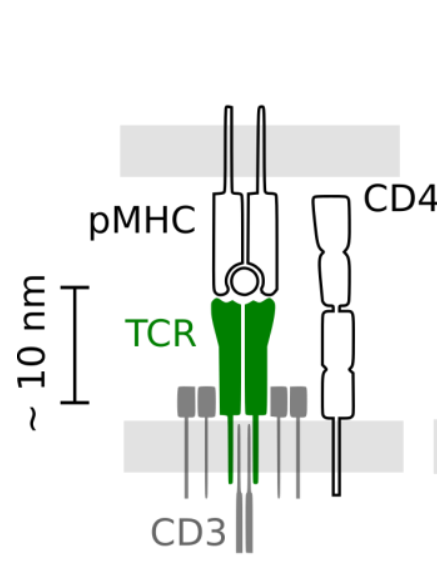

A

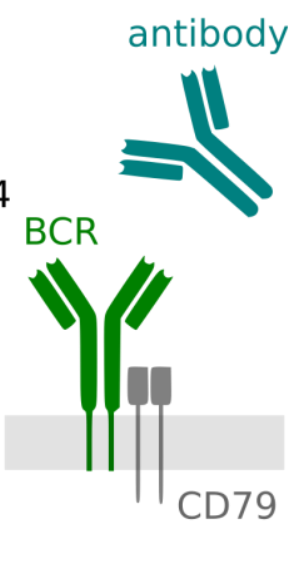

B

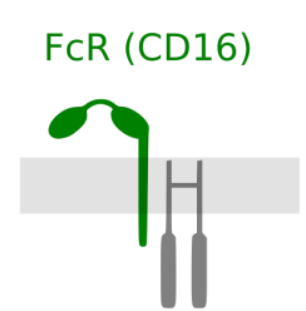

C

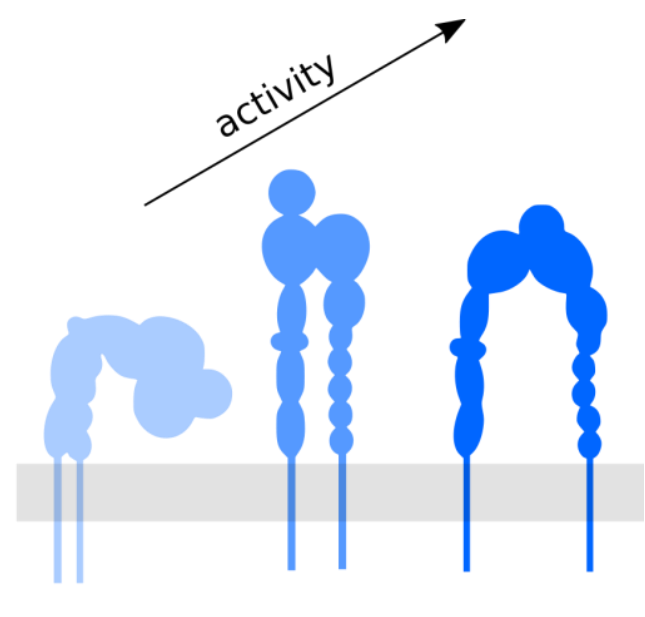

$\mathrm{D}$

Figure 1: Different types of receptors on immune cells.

A - Antigen receptor complex specific of T cell (or TCR-CD3 complex) shown with the TCR (in green, extension of its external domain 10nm) bound to its natural ligand, the peptide Major Histocompatibility Complex (pMHC), displayed by an antigen presenting cell. A co-receptor CD4 or CD8 is also shown. B. Antigen receptor complex specific of B cell (or BCR) and one antibody, the soluble form of the BCR (dimension $\sim 15 \mathrm{~nm}$ ). C. Fc Receptor present on the surface of NK cells and macrophages, binding the Fc domain of antibodies (here example of the low affinity Fc $\gamma$ RIII receptor aka CD16). D. Integrins, the main adhesion receptor of lymphocytes, represented in different conformations, corresponding to different states of activation (Nordenfelt 2016). The membrane(s) is depicted as a shaded rectangle(s). Associated proteins, exhibiting intracellular domains responsible for signal transduction, are shown in grey.

\section{Structure and generation of antigen receptors}

Antigen receptors for $\mathrm{T}$ and $\mathrm{B}$ cell are formed by sequences of immunoglobulin (Ig) domains and possess a distal hyper-variable domain (or Complementary Determining Regions, CDR), capable of recognising virtually any antigen. Each B or T lymphocyte clone displays a single type of receptor exhibiting a particular specificity for a given antigen, according to the clonal theory. The wide diversity in the specificity is obtained by an accelerated molecular evolution process alternating genetic modifications (gene rearrangements or point mutation) and receptor selection against the antigen (Murphy 2016). Importantly, the selection occurs in specialised organs (e.g. thymus) and takes place at the interface between two cells.

The B cell receptor displays two identical Fab fragments recognising the antigen, providing higher binding stability. Mature B cells secrete antibodies (Abs), derived from their BCR, which are composed of a variable fragment (Fv) identical to the BCR, and a constant fragment $(\mathrm{Fc})$ (Murphy 2016). The Fv is responsible for the antigen recognition, and the Fc determines the functional property of the Ab. Thus Fc Receptors of NK cells or macrophages bind the Fc fragment of antibodies and are formed by $2 \mathrm{Ig}$ domains. While Fc receptors are not antigen receptor per se, their capability to bind Fc fragment confer them indirectly an antigenic-like specificity. The relative role of the specificity will depend on the relative affinity on the Fc receptor side and on the antigen side. For low affinity Fc receptors, antibody may likely cover the antigenic target first, while the situation may be reverse for higher affinity Fc receptors.

The T-cell receptor is a hetero-dimer very similar to a Fab fragment of immunoglobulin and directly anchored in the membrane. It possesses a very short cytoplasmic domain which is not implicated in transferring the signal to the inside of the cell. TCR is found associated with the CD3 complex which provides different cytoplasmic domains in charge of signalling. Associated with antigen receptors are co-receptors CD4 (or CD8) on T-cell surface, recognising directly MHC class II (class I, respectively) (Murphy 2016). 


\section{Molecular recognition and binding kinetics}

The central function of antigen receptors is to recognise their antigen. This recognition occurs by the fitting of the encountering protein surfaces at the atomic scale. It generates a reversible and non-covalent interaction involving a variety of physical interactions, including electrostatic, hydrogen, Van der Waals and hydrophobic forces (Murphy 2016). They determine the specificity and the affinity of the interaction.

For this reason, the measurement of binding properties in solution has long been an important asset for the biophysical characterisation and understanding of antigen receptors. As previously noticed, while relevant for the action of soluble antibodies performing inhibition of pathogens, the affinity in solution only poorly reflects molecules behaviour at the surface of cells as well as between cells (Malissen and Bongrand 2015). The possible motions, active or passive (undulations) of the cell surface / membrane induce a non-equilibrium situation where kinetic constants become the most relevant ones to evaluate. Thus, rather than equilibrium affinity, on-rate and off-rate were measured in order to predict receptor recognition properties (Aleksic 2010). At the surface of cells, multivalency effects, for example due to divalent antibodies, change the effective concentration or binding constant. This effect is contained in the concept of avidity (Mammen 1998, Fasting 2012). The same occurs between cellular surfaces for the bridging function of antibodies as well as for the common functioning situation of monovalents BCR and TCR (Huppa 2010, Huang 2010). This may reflect the action of rebinding effects and forces at the interface of cells which are known to modify kinetics rates (Bell 1978; Seifert 2002). As a consequence, the kinetic "constants" should be rather considered as complex functions of distances between membranes, i.e. ligand and receptors, molecular crowding and accessibility for the formation of the bonds, magnitude and duration of applied forces, for their ruptures (Bongrand 1999; Fenz 2017; Huang 2019).

\section{Signalling by antigen receptors}

Upon antigen binding, immune cells should respond appropriately via intracellular signalling toward gene regulation and cytoskeleton reorganisation. BCR, TCR and FcR have membrane domains, but no identified signalling cytoplasmic domains. However, these receptors are part of protein complexes, with different components harnessing specific functions. Signalling occurs via membrane-bound proteins which are non covalently associated with protein possessing the extracellular receptor domain the receptor and possessing an intracellular domain with one or several ITAM domains (immuno-receptor tyrosine-based activation motifs) (Figure 1).

For the TCR, these are the CD3 complex and zeta chains. For the BCR, the Ig alpha and Ig beta. For the FcR, they are connected to ITAM and ITIM domains (Getahun 2015).

The precise mechanisms of phosphorylation upon antigen binding has been extensively studied in T-cells (Van der Merwe and Dushek 2011). Further signalling occurs upon phosphorylation by the recruitment of tyrosine kinases and adaptor proteins, which then target classical signalling pathways like G-proteins and second messenger such as calcium and phosphoinositides. An important aspect of signalling involves cytoskeleton remodelling, which has been also shown to control BCR diffusion and signalling (Treanor 2010). Co-stimulation through CD28 can also be involved in the TCR case. Inhibitory signal through receptors with phosphatases (CD45 for T-cells) or ITIM domains in the case of NK cells are also playing a role. Integrins (LFA-1 and VLA-4), in addition to their adhesive role, appear to increase the BCR and TCR sensitivity to antigen (Springer and Dustin 2012). Other important co-receptors and signalling proteins, which precise function will not be detailed here, include CD19/CD21/CD81 which amplify the BCR signalling and the inhibitory receptors CTLA-4 and PD-1 that suppress T cell activation. The subtle balance of activator and inhibitory signal leading to cell activability and subsequent activation are only beginning to be understood (Vivier 2004, Chiossone 2018). 


\section{OPEN QUESTIONS}

We will, in the next sections, summarise some data and concepts that have been proposed over the last decades to answer the following questions, which are at the core of the most recent research on immune cell membrane receptors structure and function in the frame of the immune response:

(i) How are molecules organised at the membrane, before and after recognition?

(ii) What are the relevant physical parameters at molecular scale to describe the physiology of recognition?

(iii) How is the message transmitted through the membrane and beyond in the cytosol and integrated at cellular scale ? These elements are central for building integrative models which could unify the different time and space scales of observed data into the physiological, cellular responses of the defence system of the body.

\section{ENGINEER, MEASURE, PERTURB}

Different experimental approaches have been applied, adapted and even developed to study immune receptors organisation and force regulation in their cellular, membrane context for the most of them. We have divided the recent methodological progresses into three categories: i) simplify or mimic the system using tools of genetic engineering, soft matter, or material sciences ii) observe molecular organisation within the membranes with higher time and space resolution using new optical microscopy modalities iii) apply controlled / localised perturbations on molecules and cells using physical and mechanical instruments. These strategies are represented on Figure 2. Some strategies may overlap partly or be combined synergistically. An overall goal consists in obtaining better quantification and degree of control of these systems, for example by measuring receptor diffusion and velocity, co-localisation, interaction forces, kinetic constants, cellular visco-elastic properties.

\section{Reductionist and bio-mimetic engineering approaches}

Immune cells present the great advantage, for in vitro studies, of acting as isolated cells, even if their state and environment plays a crucial role in their behaviour. Various cell lineages as well as primary cells isolated from blood or various organs can be studied in vitro. Additionally, immune cells generally act by direct one-to-one contact with other immune cells or infected cells, generically called Antigen Presenting Cells (APC). Some early progresses have been done in the description of immune receptors in action by replacing the APC by a glass substrate functionalised with ligands, such as antibodies or recombinant proteins, as well as supported-lipid bilayers, serving as surrogate APC (examples include Grakoui 1999 for T-Cell, Natkanski 2013 for B-Cell, Bertolet 2016 for NK-Cell). This permits a direct visualisation of receptor organisation at the cell-glass interface using fluorescence and high resolution microscopy (Figure 2A). This situation has been particularly exploited recently for super-resolution microscopy (see next section). Additionally, this strategy allows a precise control of the nature, average orientation and amount of ligands presented on the artificial surface to decipher the role of chemical stimulations. There has been also a constant effort to control more and more precisely the physical environment of the ligands in order to mimic one or more properties of cellular membranes and cellular material (Figure 2A); this approach is often guided by the idea of mimicking as closely as possible the observed properties of APCs (Hivroz and Saitakis 2015). Metal barriers have been used to confine mobile ligands bound to a supported bilayer (Mossman 2005) mimicking corralling effects of the APC's cytoskeleton (Comrie 2015); ligands have been presented on islands of different spacing and size varying from micron (Doh and Irvine 2006), to sub-micron (Pi 2013, 2015) and nanometer (Delcassian 2013) scales. This helps to assess the role of different length scales on receptor behaviour and to reproduce various spatial organisations of receptors on the APC (Figure 2B). The effect of ligand mobility was explored by comparing ligands on fluid lipid bilayers and the same ligands immobilised on glass, maintaining also a precise control and reduction of non-specific interactions (Dillard 2014). The effect underlying substrate stiffness was studied in a wide range using different types of elastomers (Wahl 2019). Patterning and substrate stiffness can also be controlled at the same time (Alameddine 2017). Overall, these approaches have provided a wealth of detailed information on the immune synapse, and recent developments may help in diagnosis (Cretel 2011) and therapeutics design (Mensali 2019) as well as bridging molecular and cell scales (Liu 2019). However, the cross-talk between effector cells and APCs, as well as the interactions in a 3D environment remain difficult to address with these strategies. Besides, the growing knowledge about various immune cell activation states, as well as tissue specificity, sets some limits on an exclusive in vitro approach.

A different and complementary approach consists in modifying selectively or reconstructing parts of the immune cell receptor machinery. Genetic engineering was used to express the immune receptor and certain co-receptors in a nonimmune cell vehicle to decipher the minimal ingredients necessary for immune response (James and Vale 2012). Alternatively, a selection of these receptors could be associated with the membrane of Giant Uni-lamellar Vesicles, a common strategy to produce model cells (Limozin 2003; Puech 2004; Fenz and Sengupta 2012; Hui and Vale 2012; Carbone 2017). Finally the receptor itself can be replaced by engineered variants to modify the degree of recognition between receptor and antigen and assess the functional consequences on immune cell activation. This strategy was applied using complementary DNA -strands of known binding kinetics to replace the TCR (Taylor 2017). A similar approach where the T-cell receptor is replaced by an antibody fragment (Chimeric Antigen Receptor or CAR) possesses 
a high potential for cell immunotherapy in cancer (Roybal 2016), and in growing academic and industrial fields of research.

\section{Increase spatio-temporal resolution of observables}

The tremendous progress of fluorescence imaging, associated with genetically encoded fluorescent proteins, have reached the field of immune receptors in the recent years. The lymphocyte/surrogate APC configuration (Figure 2A) permits high resolution total internal reflection (TIRF) microscopy used to study antigen receptors organisation in fixed samples at the scale of ca. $20 \mathrm{~nm}$ by single molecule localisation microscopy (SMLM) (Lillemeier 2010; Shelby 2013; Baumgart 2015; Pageon 2016; Jung 2016). TIRF was also used for dynamic studies of the fluorescently labelled membrane of primary T cells (Brodovitch 2013, 2015). Increased resolution was obtained by structured illumination microscopy (SIM) to decipher dynamic actin structure at the synapse (Murugesan 2016). Light sheet microscopy (LSM) was used to monitor cell dynamics in 3D at $0.1 \mu \mathrm{m}$ spatial resolution and second time resolution (Chen 2014; Cai 2017). Alternatively, Reflection Interference Contrast Microscopy allows to follow membrane conformation of live cells at a surface without labelling (Limozin and Sengupta 2009, Dillard 2014, Benard 2018, Gonzalez 2019). The increased spatio-temporal resolution describing membrane and cytoskeleton resolution gives important insights on the structural base and environment of immune receptors, together with their impact on cell morphology and motion.

Fluorescence is now widely used to measure spatio-temporal parameters of antigen receptors. Labelling strategies vary from genetically encoded fluorescent probes to variants of fluorescently labelled antibodies. Diffusion of a population of receptors is measured by Fluorescence Recovery After Photobleaching FRAP (Dushek 2008). Diffusion of individual receptors is measured by Fluorescence Correlation Microscopy FCS (Gakamsky 2005; Guia 2011; ChouakiBenmansour 2018), which measure transit time of a fluorophore in a focal spot or single particle tracking SPT (Manz 2011). Nanometer scale co-localisation is measured by Forster Resonance Energy Transfer FRET between a donor and an acceptor fluorophores. Innovative protein or peptide constructions can use FRET to report various signals. Thus phosphorylation levels of certain molecules, downstream of TCR, can be measured using specific reporters (Cadra 2015). Similarly, calcium fluxes, that are a common robust marker of the interpretation of a membrane signal for immune cells, can be measured using innovative reporter molecules, either chemical ones or genetically encoded ones (Palmer 2006; Salles 2013). Polyethylene glycol, DNA or peptide linkers with known elastic properties can serve as molecular force probes emitting a FRET signal dependant on the molecular extension (Ma 2016). Thus forces exerted by single receptors can be imaged at the cell-surface interface and quantified in the 10pN range (Figure 2C).

Current practical limitations come from the existing trade-off between spatial and temporal resolution, inherent to super-resolution strategies. It is particular significant for immune cells which exhibit fast and large concomitant reorganisations in their shape and protein distribution at their membrane.

\section{Mechanical perturbation}

A range of techniques coming from single molecule physics and material sciences has been now adapted to study individual immune receptors or bonds, as well as their behaviour in the cellular context. Mechanical perturbations are applied through an external force field or a mechanical actuator. Forces are measured from the deformation of a spring constituted by a cantilever, a deformable cell, an optical beam or a flexible molecule. Measurements and stimulations can be performed on isolated purified proteins (acellular context) or directly on cells. We review here the main methods applied to immune receptors and cells. Biological results are discussed in the last chapter.

The Laminar Flow Chamber (LFC; Figure 2D) uses an hydrodynamic flow to convect cells or antigen functionalised microspheres above a surface coated with purified receptors. The method allows direct measurements of the lifetime of receptor-antigen complexes as well as a precise control of their association (Robert 2011; Limozin 2016). With the use of microspheres, the force range applied on individual bonds is 5-50 pN. Recent application showed that the unique ability of LFC for simultaneous measurements of association and dissociation can be instrumental to assess the kinetic properties of single TCR-pMHC bonds (Limozin 2019).

The Bio-membrane Force Probe (BFP; Figure 2E) is based on micropipette aspiration of the cell of study and of a red blood cell serving as a ultra-soft spring and carrying an antigen-decorated bead. This was used to bind and stimulate a lymphocyte via its receptors and monitor calcium flow and suggest for the first time that TCR-pMHC exhibit catch bond behaviour (Liu 2014). The force range is from $0.1-10 \mathrm{pN}$ in the lateral direction, normal to the bead or cell surface. Micropipettes and micro-needles can also be used to control force and time in the interaction between one lymphocyte and an antigen-covered bead (Sawicka 2017). The method can easily be coupled with fluorescence measurement to assess cell response, e.g. by following the burst of calcium flux (Liu 2014). It was also extensively used for phagocytosis studies, where an antibody-coated bead or a parasite is presented to a neutrophil or a macrophage, taking advantage of the lateral view of the bead-cell contact (Heinrich 2015).

Atomic Force Microscopy (AFM; Figure 2F), which uses a micro-cantilever with a nanometric tip to contact or bind a sample, was used to pull on antigen receptors at the cell surface (Puech 2011). The accessible force range is from 10pN to several $\mathrm{nN}$ in the vertical direction. The method can be coupled to fluorescence imaging to read a cellular response for example via calcium signals (Cazaux 2016; Hu and Butte 2016) and can even be extended to study the interaction between a T cell and an APC (Hoffmann 2011). While useful to perform localized time-controlled stimulations by 
contact, the technique can also serve for measuring mechanical response of the cell and its evolution upon a stimulation (Franz and Puech 2008).

Optical Tweezers (OT; Figure 2F), which use a strongly focus infrared beam creating an optical trap to capture a microsphere, were used to stimulate the cell surface and applying force in a controlled direction (Kim 2009; Feng 2017). This unique feature was used to demonstrate that the TCR responds differently to forces applied in directions lateral (shearing) or normal (pulling) to the membrane (Feng 2017). The force range is typically 1-50 pN in horizontal direction, and about 3 times less in the vertical direction. The technique was also applied on purified proteins to measure receptor-antigen rupture under force (Das 2015). The force curve obtained upon membrane tether pulling can be analysed to probe membrane tension (Masters 2013) or the receptor link to the cytoskeleton, as already achieved with the BFP (Evans 2005).

A

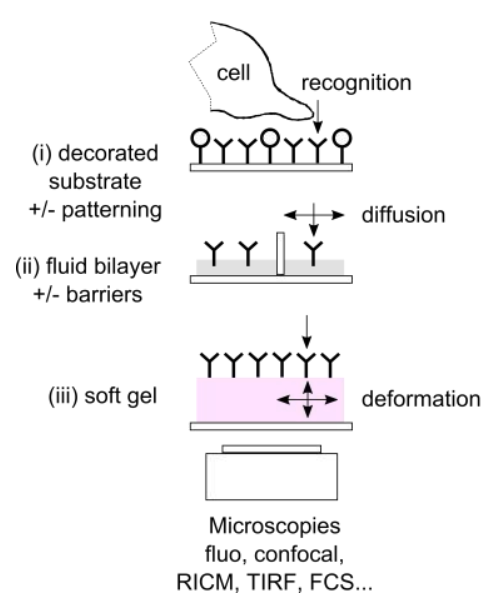

B

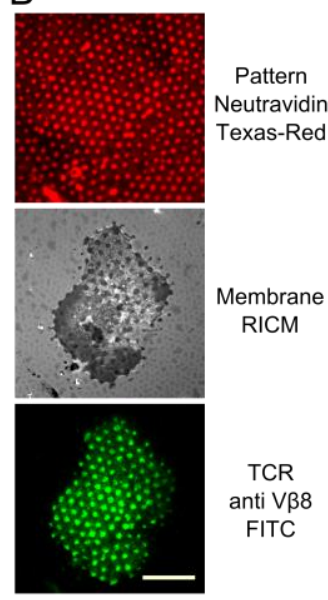

C

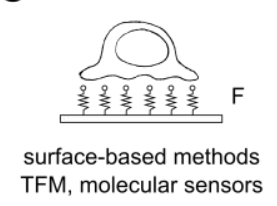

$\mathrm{E}$

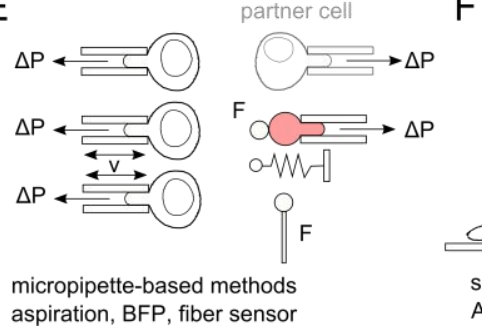

D

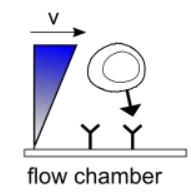

$\mathrm{F}$

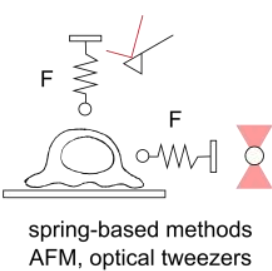

Figure 2: Various surface and force-based methods to study antigen receptor organisation and binding.

A. The antigen presenting cell is replaced by an artificial substrate with well defined physico-chemical features. The nature, number and position of the molecules presented, as well as their physical environment, can be controlled. This configuration is compatible with various high-resolution optical microscopy modalities, including RICM, TIRF, FCS and SMLM. B. Examples of microscopy images of substrate with sub-micron pattern of anti-CD3 imaged in epifluorescence (top), lymphocyte membrane imaged in RICM (middle) and fluorescently labelled TCR imaged in TIRF (bottom). Bar $=10 \mu \mathrm{m}$. C. Surface and molecular force sensors. In a situation analogous to A, the "surrogate cell substrate" can be used to measure the forces exerted by the cell either by monitoring substrate elastic deformation via embedded beads or using force sensitive FRET-based molecular probes. D. Laminar flow chamber. An hydrodynamic flow is convecting cells or microspheres functionalised with receptors above a surface coated with antigens; the kinetics of on/off binding are obtained by recording parallelly the particle arrests duration and detachment by fast videomicroscopy (Robert 2011; Limozin 2019). E. Micropipettes-based methods. A cell is aspirated in a pipette to measure cell membrane or cortical tension. An APC cell can be put into contact and eventually pulled away (Sung 2006). Alternatively, another pipette holding an aspirated red-blood cell serving as a spring is used to present a functionalised bead for measuring receptor-ligand interaction (Bio-membrane force probe; Evans 2005; Kinoshita 2010). The second pipette can be replaced by a sensor fibre (Sawicka 2017). F. Spring-based methods used to apply and measure localised forces. Atomic force microscopy uses a soft cantilever while optical tweezers uses a highly focused infrared light beam trapping a bead.

\section{FROM MOLECULAR TO CELLULAR SCALES}

\section{Antigen receptor conformations and cis interactions}

Receptor diversity encoded in the CDR is responsible for its specificity and affinity for the antigen (Murphy 2016; Pecht 2018). Since antigen receptors are deprived of cytoplasmic domains, a long-standing question was to understand how antigen binding is triggering downstream intracellular signal, i.e. passing through the membrane. One hypothesis is that antigen binding may lead to conformational changes in the receptor protein or its direct environment affecting its organisation and reactivity. Nuclear Magnetic Resonance studies have revealed that the cytoplasmic tails of CD3 change conformation upon antigen binding, by detaching from the membrane and providing an access for their phosphorylation sites ITAM (Xu 2008). Numerical simulations have suggested recently that a conformational change of the TCR alpha transmembrane domain changes its orientation during binding, which leads cytoplasmic tails of the CD3 
to reorient for phosphorylation (Brazin 2018). As detailed later, force exerted on the molecule upon binding maybe a driving parameter to trigger a conformational change of the subunits of the TCR (Ma 2009; Feng 2015).

Since TCR can not be efficiently activated by soluble monomeric pMHCs, it has been proposed early that receptor triggering may occur through multimerisation of the receptors (Figure 3A). Antigen binding favours the formation of clusters of TCR, identified early by TIRF microscopy (Varma 2006). It was proposed that these clusters serve as signalling platforms (Dustin and Groves 2012). Progresses in super-resolution imaging have evidenced cluster of smaller and smaller size, down to nanometer sizes, questioning the realm of micron-size clusters initially observed (Pageon 2016; Liu 2016a). Additionally, the resting state of the membrane is still the subject of contradictory studies, reporting either preformed clusters (Crites 2014) or their absence (Rossboth 2018). Vale and colleagues reconstituted in vitro a collection of essential signalling proteins on a lipid bilayers and observed protein phase separation following initial instants of molecular recognition at the membrane surfaces ( $\mathrm{Su} 2016$ )

By analogy with the TCR, the mechanism of triggering of the BCR was also thought to be based on receptor dimerisation, suggested by the early observation that the BCR is not activated by soluble monovalent ligands. This hypothesis was challenged by a quantitative bi-fluorescence complementation assay, suggesting that the resting state of BCR on the cell membrane was already oligomeric (Yang and Reth 2010), and that BCR activation was dependent on its immunoglobulin class (Übelhart 2015). BCR oligomers were also shown to be open by treatment with different monovalent stimuli (Volkmann 2016). As in the case of the TCR, there is no current consensus on the pre-existence of clusters prior to antigen binding (Liu 2016a). Additionally, how force may influence this organisation upon antigen binding is still unknown.

For Fc Receptors, the classical hypothesis for their triggering relies on cross-linking, like assembly or concentration mediated by the binding of opsonised targets densely covered by Ig (Murphy 2016). However, mobile receptors can also trigger FcRI receptors on mast cells (Carroll-Portillo 2010). To our knowledge, no consensus exists on the resting distribution of these receptors.

\section{Membrane regulation of antigen receptor organisation}

After being long underestimated, due to a dominant view of the involvement of protein receptors, the lipid membrane composition, domain organisation and its mechanical state are now more and more considered as a regulator of antigen receptor organisation and triggering.

$\mathrm{T}$ cell activation is regulated by various lipid membrane components including phospholipids, cholesterol and phosphoinositides (Wu 2016). Lipid nature and organisation in rafts could typically modulate antigen receptors conformation, mobility and interactions (Wu 2016). Early studies with raft markers have suggested the involvement of cholesterol-rich micro-domains associated with TCR clustering (Gaus 2005). The acidic phospholipids of the membrane help sequestering the CD3 cytoplasmic tails, preventing phosphorylation prior to antigen binding (Xu 2008). The role of phosphoinositide de-phosphorylation in this process was supported by the measurement of augmented TCR mobility by FCS (Chouaki-Benmansour 2018). Lipids and derivatives are also key messengers of cell activation, e.g. PIP2, PIP3, DAG for T cell activation pathways (Murphy 2016).

For FcRI on mast cells, an increase in receptor clustering was observed upon by SMLM calcium stimulation (Shelby 2013). Membrane cholesterol content was found to play a role in this change. More generally, lipid composition induced phase separation in the plasma membrane could be a driving force for receptor reorganisation and triggering, as shown for the BCR again using SMLM (Stone 2017).

Membrane tension is primarily involved in phagocytosis, the process by which certain immune cells engulf their targets, by regulating membrane trafficking and biochemical signalling (Masters 2013). Increased tension modifies small GTP-ase action and repartition as well as cytoskeletal organisation, which in turn regulates receptor signalling in macrophages (Masters 2013). Similar mechanisms are probably also involved in signalling by the TCR and BCR (Rossy 2018). For example membrane tension may affect $\mathrm{Ca}^{2+}$ influx (Cazaux 2015). Recently, the professional mechanotranductor membrane channel Piezo1 was found to regulate $\mathrm{T}$ cell activation, supporting the role of membrane tension in TCR triggering (Liu 2018).

\section{Trans interactions and force regulation}

Interactions of antigen receptor with their ligand occurs in many instances at the interface between two cells. The proximity and the interactions between the two cell surfaces influences deeply reaction kinetics, which in turns determine antigen recognition. This has lead to use of the concept of 2D reactions (Zarnitsyna and Zhu 2012; Malissen and Bongrand 2015). Compared to reactions in solution (3D), increased off-rate and increased on-rate were measured between TCR and pMHC for T cells interacting with an artificial surface, resulting in an increased 2D apparent affinity (Huppa 2010). The accelerated off-rate was observed in particular for agonist peptides (Huang 2010). Later studies showed that cooperative binding of TCR-pMHC and CD28 co-receptor was achieved globally upon antigen recognition by increased on-rate (Pielak 2017). Furthermore, simultaneous monitoring of T-cell activation and counting of each binding and unbinding events by single particle tracking reveal long tails distribution in dwell times involved in cellular activation (Lin 2019). This shows that reactions at the interface are modified in a complex manner at the cell-cell interface, and that a small number of outlier events could be responsible for cell scale response. 
In this context, it became crucial to measure individual TCR-pMHC bond kinetics under controlled force. The first study in an acellular context, using LFC on purified proteins, revealed that an applied force was usually increasing offrate, and that, for a series of peptide of variable $\mathrm{T}$ cell activation potency, a better correlation between off-rate and cytokine production was obtained for an applied force around $40 \mathrm{pN}$ (Robert 2012). Experiments with BFP showed that T-cell activation, as monitored by intracellular calcium fluxes, was correlated with a catch bond behaviour of the TCRpMHC bond with a peak in lifetime for around $10 \mathrm{pN}$ (Liu 2014). Since, one single group observed a catch bond behaviour in an acellular system (Das 2015), whether the catch bond behaviour observed in cellular context (Liu 2014; Sibener 2018) is solely encoded in the TCR-pMHC bond is questionable. A recent study suggests that the intracellular coupling of CD8 with TCR-pMHC is determinant to observe the catch bond behaviour (Hong 2018). Indeed, new cellfree measurements (i.e. without implication of co-receptors) of association and dissociation showed that no catch-bond behaviour of single TCR-pMHC interactions for a set of five activating peptides could be evidenced (Limozin 2019).

The BCR-antigen bond may also be submitted to force during antigen recognition and endocytosis by the B lymphocyte (Natkanski 2013; Wan 2015; Pierobon and Lennon-Dumenil 2017; Spillane and Tolar 2018). Therefore, it is relevant to study the force dependence of this bond to account for the physiological context of the BCR as well as in situation where the antibody bridges cellular structures between antigen and Fc receptor. Early AFM study revealed a good correlation between antibody unbinding force and their thermal dissociation rate (Schwesinger 2000). BCR and classical antibodies are also good models to define more strictly and study quantitatively the concept of avidity of divalent or multivalent receptors (Lo Schiavo 2012). While antigen-antibody bonds would generally exhibit a slip bond behaviour, a catch bond characteristic was recently evidenced for a single domain antibody - Fc Receptor bond using the LFC (Gonzalez 2019).

\section{Size-based lateral organization of receptors}

When two cellular surfaces form a close contact like in the immunological synapse, the efficient binding between receptors and ligand on each side is highly dependant on the relative size of the molecules which form the bonds. The archetypal immunological synapse is traditionally described as concentric rings of molecules establishing a hierarchical topography between the T cell and the APC (Figure 3B). It is formed after several minutes of adhesive contact with a surrogate APC and extends on about $10 \mu \mathrm{m}$ diameter. The central adhesion patch contains TCR-pMHC bond, surrounded by an adhesive ring of integrins LFA-1-ICAM bonds, and an external ring of CD45 and other glycoproteins (Yokosuza and Saito 2010). It was shown that elongating the ectodomains of pMHC was reducing T-cell activation, suggesting that a close apposition of membranes is necessary for TCR triggering (Choudhuri 2005). A possible mechanism involves the exclusion from the contact zone of the long glycoprotein CD45 by steric repulsion (Figure. 3B), which was recently reproduced in a bio-mimetic system (Carbone 2017). CD45 cytoplasmic tail exhibit phosphatase domains which exclusion may favour kinase action in a kinetic segregation model for TCR triggering (Van der Merwe and Dushek 2011). Recently, it was shown that TCR could be dispensable for T cell activation in case of sufficient CD45 local exclusion (Chang 2016). However, additional mechanisms involving coupling of long glycoproteins like CD43 to the cytoskeleton via adapter protein moesin, may contribute to alter the topography of the immune synapse (Delon 2001). The supramolecular organisation of the synapse was also proposed to be adapted to the migration phase displayed by lymphocytes by a symmetry breaking leading to a kinapse (Dustin 2008).

Examination of earlier contacts between T cell and a surrogate APC revealed the existence of micro adhesion-rings, reproducing the supramolecular organisation of the synapse at a subcellular scale (Hashimoto-Tane 2016). The dynamic interplay of intercellular bond formation and rupture with the topographical constraints and lateral phase separation remains to be understood in the cell context (Schmid 2016). Moreover, the exact role of the complex structure of the mature IS remains to be established. For B cells, similarly organised synapse are the zones where antigen extraction is performed from opposing surfaces, being artificial or cellular (Spillane and Tolar 2018). The relative size of activator and inhibitory receptors was shown to regulate the balance responsible for NK cell activation (Köhler 2010). Using a reconstituted model of antibody opsonised target, Fletcher et al. recently showed that phagocytosis was strongly reduced for antigens larger than $10 \mathrm{~nm}$, and that this was due to the lack of exclusion of CD45 from the cell-target contact zone (Bakalar 2018).

\section{Cytoskeleton-receptor interaction and force generation}

The importance of actin cytoskeleton in $\mathrm{T}$ lymphocyte activation was recognised early by use of pharmacological perturbations (Burkhardt 2008). The TCR micro-clusters at the immune synapse display a centripetal motion linked to actin cytoskeleton tread-milling, as observed on surrogate APC with TIRF microscopy (Varma 2006). Substrates composed of metallic barrier partitioning a functionalised supported bilayer were used to hinder TCR motion by blocking their ligand, suggesting that a frictional coupling between cytoskeleton and receptor was operating (Mossman 2005). Using structured illumination microscopy, TCR micro-clusters were shown to be propelled by actomyosin arcs within the immunological synapse (Murugesan 2016). Sorting mechanisms leading to the segregation of antigen receptors and adhesive molecules observed in the synapse may also rely partly on corralling or even differential binding to the cytoskeleton (Hartman 2009). The interaction of integrin LFA-1 with the actin cytoskeleton and upon binding to its immobilised ligand ICAM on the dendritic cell helps to modulate integrin activation by a conformational change and adhesion regulation (Comrie 2015). In turn, regulation of the integrin-actin link by adapter proteins may strongly 
influence the actin retrograde flow, providing a feedback to antigen receptor signalling (Jankowska 2018). The comparative use of substrates exhibiting immobilised or mobile anti-CD3 in combination with cytoskeletal drugs evidenced the instrumental role of actin-receptor friction in T cell spreading (Dillard 2014). The same driving force produced by the actin retrograde flow was also proposed, in combination with ligand-receptor force dependent unbinding, to explain the optimal substrate stiffness observed for TCR-mediated spreading (Wahl 2019) (Figure 3C). The interaction of actin and TCR was also proposed to be responsible for TCR triggering by inducing conformational change upon ligand binding (Feng 2017). More generally, actin dynamics may be a generic mechanism for T cells to adapt the time and length scales of their activation (Colin-York 2019). TCR actin interaction probably occurs nonspecifically by corralling effects but the existence of a direct molecular link is still lacking experimental evidence. Additionally, cross-talk between TCR and LFA-1 regulates adhesion as well as potentially the interaction of both receptors with the cytoskeleton (Benard 2018).

BFP studies had first shown force generation by the T lymphocyte upon receptor triggering by an anti-CD3 coated bead, with an initial pushing followed by pulling (Husson 2011). More recently, using AFM, force was shown to require TCR engagement and to precede calcium flux, a common marker of T cell activation (Hu and Butte 2016). DNA-based tension sensors were used to measure pulling forces exerted by single TCR, in the 10-20 pN range (Liu $2016 \mathrm{~b}$ ). Consistently with BFP studies discussed above (Liu 2014), it suggests a possible cellular mechanism used to enhance antigen discrimination by force application.

Actin is also regulating B cell response to antigens by controlling BCR diffusion and by force generation in the immune synapse (Tolar 2017). Antigen discrimination by internalisation following BCR binding was found to be actin dependent, and force dependent, as shown by the use of AFM (Natkanski 2013). Using molecular force sensor, the BCR was later shown to exert a direct pulling force on the antigen (Spillane 2017). As for $\mathrm{T}$ cells, force generation in their key functional events makes the B cell naturally sensitive to substrate stiffness (Zeng 2015).

For Fc receptors, force induced mechanisms are commonly accepted in phagocytosis (Ostrowski 2016). Integrins regulate Fc receptor aggregation by creating an adhesive physical barrier to their diffusion (Freeman 2016). Interestingly, the actin cytoskeleton is also involved in this corralling effect via transmembrane glycoproteins interacting with the extracellular matrix and operating as cytoplasmic pickets (Freeman 2018). F-actin network at the lytic synapse of $\mathrm{T}$ and NK cells was shown to be crucial in controlling lytic vesicle release by nanoscale actin dynamism (Carisey 2018). By analogy to the cytotoxic synapse of $\mathrm{T}$ cells, force are also expected to occur at the NK cell synapse or during their formation (Matalon 2018), as recently suggested by the use of force-dependent anti-CD16 nanobodies (Gonzalez 2019).

\section{Membrane ultra-structure during cell exploration and adhesion}

The close link between receptor organisation and cytoskeletal dynamics evidenced in the immunological synapse is suggesting that this association maybe relevant in various cell membrane ultra-structures at different scales and at different steps of lymphocyte function (Figure 3). The interplay of membrane dynamics and structure with TCR signalling was reviewed recently (He and Bongrand 2012, Pettman 2018). Brodovitch et al. have observed the change in filopodial dynamics upon specific binding (Brodovitch 2013). A subsequent study using light sheet imaging, has described how filopodia explore efficiently their environment (Cai 2017). One has to note that the mobilisation of the actin cytoskeleton upon TCR triggering was noticed early (Valitutti 1995). The situation is now seen as more complex, since (i) TCR clusters were shown to promote the nucleation of actin foci by the WASP pathway (Kumari 2015) and (ii) conversely, cell protrusions were shown to organise antigen receptors: microvilli (Jung 2016; Razvag 2018), lamellipods (Varma 2006; Ritter 2015). One intriguing point, not yet clearly addressed, is whether the cytoskeleton only 'corrals' the TCR in membrane regions and related molecules (together with potential lipid raft effects) or if a 'direct' link of TCR to cytoskeleton exists which may explain e.g. its mechanosensitive properties, in particular solve the controversy about the TCR being able of behaving as a catch bond. 


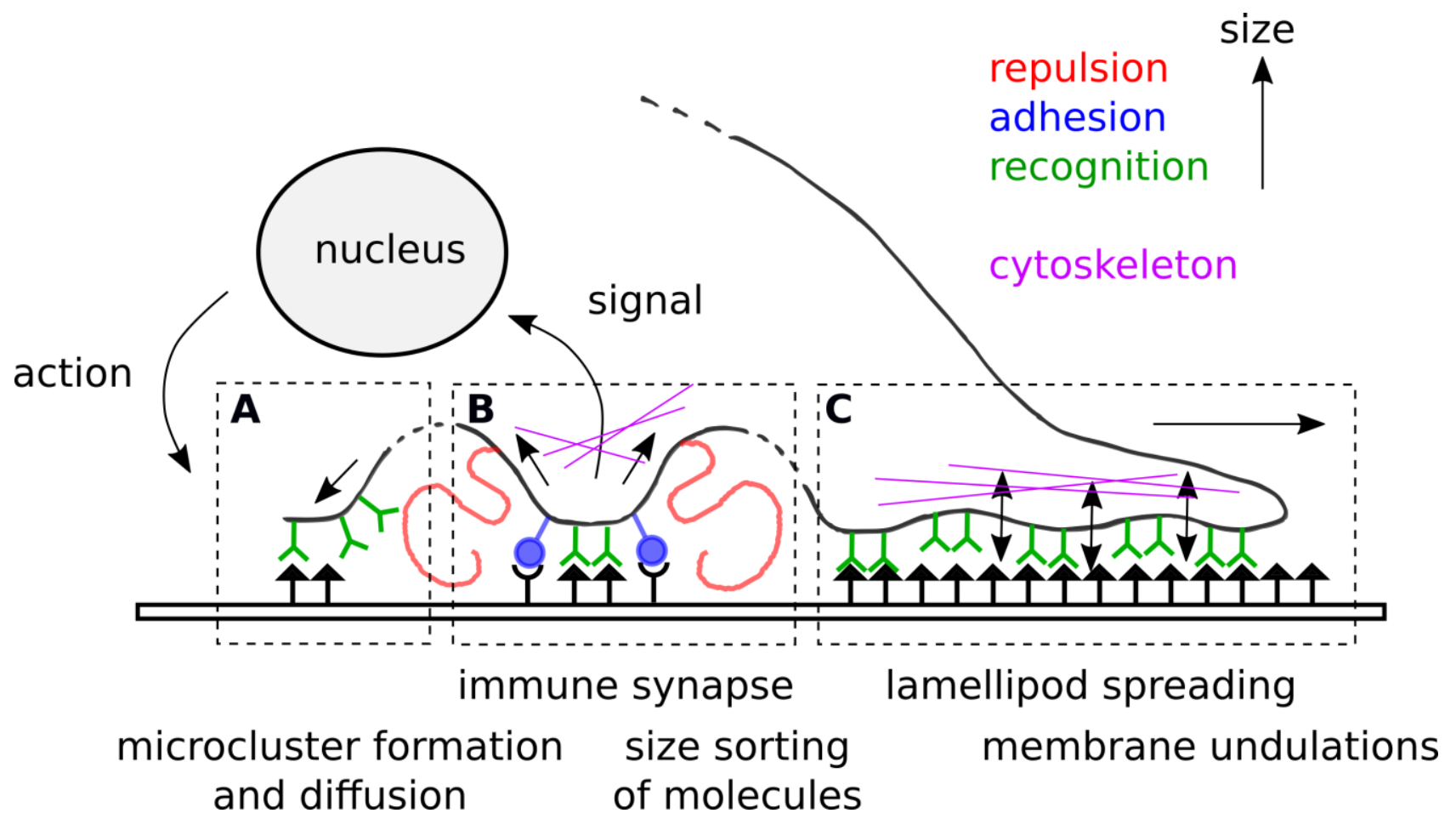

Figure 3: Schematic overview of receptor organisation and dynamics at the lymphocyte cell membrane at different stages of recognition and/or under various experimental conditions.

The lymphocyte interacts with an artificial surface acting as a surrogate APC. Receptors are shown in different subcellular contexts, which can be representative of different steps in lymphocyte physiology. Receptors of increasing size are shown: antigen receptors for molecular recognition (green); adhesion receptors like integrins for adhesion (blue); proteins of the glycocalyx like CD45 for repulsion (red). Membrane and receptors may interact with the actin cytoskeleton represented in purple. Receptor triggering induces signalling to the nucleus which feedbacks to the membrane and cytoskeleton. A. Micro-cluster formation and diffusion. B. Formation of small scale or large scale immunological synapse with size sorting of molecules, potentially serving at a platform for either signalling efficiently, which in turns may affect membrane structure and dynamics, among other, though triggering specific cellular programs in the frame of the TCR, or as a recycling / extracting platform for e.g. antigens in the frame of the BCR. C. Lamellipodial extension during cell spreading or migration, which may include membrane undulation and actin retrograde flow.

\section{Modelling and integrating experimental data}

Progresses in molecular dynamics have permitted to study the structure of antigen receptors in interaction with their ligand, illustrating the effect TCR-pMHC docking geometry on activation (Adams 2011). For the BCR, modelling of the hinge region was used to predict the valency effect of different antibody classes (Übelhart 2015). More recently, it was suggested that activating peptides may rely on catch bonds, but it is still delicate to rely finely measured kinetic properties to observed or calculated structures (Sibener 2018). Thus, recent data obtained with the laminar flow chamber suggesting the need of a minimal encounter time for TCR-pMHC association can not be linked yet to a detailed structural base (Limozin 2019).

Attempts to integrate experimental data at a slightly larger scales, are exemplified by the variations proposed around the kinetic segregation model of TCR triggering (Van der Merwe and Dushek 2011), where receptors size and lateral organization are coupled at the immune synapse. In this context, Monte-Carlo simulations may help decipher quantitatively the respective roles of lateral crowding, binding protein affinity, and thermally-driven membrane height fluctuations in membrane proteins segregation (Schmid 2016), where cytoskeleton and activity are missing.

More recently, a clutch model integrating cytoskeleton generated forces in bond kinetics was proposed to explain the non-monotonous spreading response of T-cells on substrates of increasing rigidity (Wahl 2019). At the cellular scale, phagocytosis of antibody opsonised particles was modelled with finite elements simulations, emphasising the role of cytoskeleton-receptor bonds in driving the phagocytic cup progression (Herant 2006). 


\section{OUTLOOK}

We have seen that, when considering some of the most important receptors that are embedded in the plasma membrane of immune cells, different scales in space and time are involved. From molecular recognition to the organisation of clusters of proteins which may serve as platforms for signalling at cellular scale, from very brief molecular contacts (msec-sec) to the integration of the read signal (up to several hours for the immune response to take place), the idea has been to dissect how recognition of a danger signal modifies cell's program. Biochemical and biophysical parameters, such as chemistry and structure of the recognition pockets, geometry of the partners, mobility of the molecules in the plane of the membrane, but also the forces that may be acting on them due to cellular or membrane-cytoskeleton motion, have been identified and quantified. All in all, a large corpus of data exists, and some discrepancies are still remaining. We identified two crucial points that are sometimes under-estimated, and where the membrane is a key player.

First, recording changes in membrane structure or protein organisation when the cell is activated by a given signal requires a very good knowledge of the "starting state" of the cell. Lipid rafts and protein clusters of smaller and smaller sizes are proposed to pre-exist, a baseline of phosphorylation state has also been identified for the underlying signalling hubs, but no clear view of what the membrane looks like in its resting state exists, providing this resting state may be well defined. This is the most difficult experiment ever : how to observe something that is made to change upon the most subtle and gentle perturbation? More and more evidence points toward the fact that we know very little about that, and the most used control situation may still bias the membrane structure (Ponjavic 2018; Santos 2018).

Second, the large jumps in scale that are at play in the process leading from protein interaction and membrane apposition between an immune cell and its partner to the development of a signature of an efficient recognition (such as phosphorylation, calcium fluxes, cytokine production, cell cycle modification,...) render very difficult the establishment of causal links between diverse phenomena. At each step, non-linear effects may be at work, in order to be more robust to noise, false recognition and false amplification. Moreover, trying to block some of the signalling pathways, or even modulating the organisation of proteins at the membrane may only reveal that other mechanisms may be compensating for the deleted, more direct way. Redundancy is a key concept in this complex world of membrane receptors in immune cells.

A trivial, but argumented conclusion could be that a lot of experimental, but also conceptual work has still to be done to be able to propose an integrated view of at least the first minutes of protein recognition at cellular membrane in the context of the immune response. As briefly discussed above, in silico approaches, either at molecular scale or cellular scale, could help identifying new avenues for this field, based on existing multi-parametric data.

\section{ACKNOWLEDGEMENTS}

We thank Pierre Dillard and Fuwei Pi for the microscopy images of Figure 2B, Pierre Bongrand and Kheya Sengupta for scientific exchanges and critical reading of the manuscript, as well as all present and past members of Laboratoire Adhesion and Inflammation for numerous discussions.

\section{COMPLIANCE WITH ETHICAL STANDARDS}

Conflict of Interest: Authors declare that they have no conflict of interest.

Ethical approval: This article does not contain any studies with human participants or animals performed by any of the authors.

\section{REFERENCES}

Adams, J.J., Narayanan, S., Liu, B., Birnbaum, M.E., Kruse, A.C., Bowerman, N.A., Chen, W., Levin, A.M., Connolly, J.M., Zhu, C., et al. (2011). T Cell Receptor Signaling Is Limited by Docking Geometry to Peptide-Major Histocompatibility Complex. Immunity 35, 681-693.

Adams, N.M., O'Sullivan, T.E., Geary, C.D., Karo, J.M., Amezquita, R.A., Joshi, N.S., Kaech, S.M., and Sun, J.C. (2016). NK Cell Responses Redefine Immunological Memory. The Journal of Immunology 197, 2963-2970.

Alameddine, R., Wahl, A., Pi, F., Bouzalmate, K., Limozin, L., Charrier, A., and Sengupta, K. (2017). Printing Functional Protein Nanodots on Soft Elastomers: From Transfer Mechanism to Cell Mechanosensing. Nano Letters 17, 4284-4290.

Aleksic, M., Dushek, O., Zhang, H., Shenderov, E., Chen, J.-L., Cerundolo, V., Coombs, D., and van der Merwe, P.A. (2010). Dependence of T Cell Antigen Recognition on T Cell Receptor-Peptide MHC Confinement Time. Immunity 32, $163-174$.

Bakalar, M.H., Joffe, A.M., Schmid, E.M., Son, S., Podolski, M., and Fletcher, D.A. (2018). Size-Dependent Segregation Controls Macrophage Phagocytosis of Antibody-Opsonized Targets. Cell 174, 131-142.e13.

Baumgart, F., and Schütz, G.J. (2015). Detecting protein association at the T cell plasma membrane. Biochimica et Biophysica Acta (BBA) - Molecular Cell Research 1853, 791-801.

Bell, G. (1978). Models for the specific adhesion of cells to cells. Science 200, 618-627.

Benard, E., Nunès, J.A., Limozin, L., and Sengupta, K. (2018). T Cells on Engineered Substrates: The Impact of TCR Clustering Is Enhanced by LFA-1 Engagement. Frontiers in Immunology 9, 2085. 
Bertolet, G., and Liu, D. (2016). The Planar Lipid Bilayer System Serves as a Reductionist Approach for Studying NK Cell Immunological Synapses and Their Functions. In Natural Killer Cells, S.S. Somanchi, ed. (New York, NY: Springer New York), pp. 151-165.

Bongrand, P. (1999). Ligand-receptor interactions. Rep. Prog. Phys. 62, 921.

Boudreau, J.E., and Hsu, K.C. (2018). Natural Killer Cell Education and the Response to Infection and Cancer Therapy: Stay Tuned. Trends in Immunology 39, 222-239.

Brazin, K.N., Mallis, R.J., Boeszoermenyi, A., Feng, Y., Yoshizawa, A., Reche, P.A., Kaur, P., Bi, K., Hussey, R.E., Duke-Cohan, J.S., et al. (2018). The T Cell Antigen Receptor $\alpha$ Transmembrane Domain Coordinates Triggering through Regulation of Bilayer Immersion and CD3 Subunit Associations. Immunity 49, 829-841.e6.

Brodovitch, A., Bongrand, P., and Pierres, A. (2013). T Lymphocytes Sense Antigens within Seconds and Make a Decision within One Minute. The Journal of Immunology 191, 2064-2071.

Brodovitch, A., Limozin, L., Bongrand, P., and Pierres, A. (2015). Use of TIRF to Monitor T-Lymphocyte Membrane Dynamics with Submicrometer and Subsecond Resolution. Cellular and Molecular Bioengineering 8, 178-186.

Burkhardt, J.K., Carrizosa, E., and Shaffer, M.H. (2008). The Actin Cytoskeleton in T Cell Activation. Annual Review of Immunology 26, 233-259.

Cadra, S., Gucciardi, A., Valignat, M.-P., Theodoly, O., Vacaflores, A., Houtman, J.C.D., and Lellouch, A.C. (2015). ROZA-XL, an improved FRET based biosensor with an increased dynamic range for visualizing Zeta Associated Protein $70 \mathrm{kD}$ (ZAP-70) tyrosine kinase activity in live T cells. Biochemical and Biophysical Research Communications 459, 405-410.

Cai, E., Marchuk, K., Beemiller, P., Beppler, C., Rubashkin, M.G., Weaver, V.M., Gérard, A., Liu, T.-L., Chen, B.-C., Betzig, E., et al. (2017). Visualizing dynamic microvillar search and stabilization during ligand detection by T cells. Science 356 , eaal3118.

Carbone, C.B., Kern, N., Fernandes, R.A., Hui, E., Su, X., Garcia, K.C., and Vale, R.D. (2017). In vitro reconstitution of T cell receptor-mediated segregation of the CD45 phosphatase. Proceedings of the National Academy of Sciences 114, E9338-E9345.

Carisey, A.F., Mace, E.M., Saeed, M.B., Davis, D.M., and Orange, J.S. (2018). Nanoscale Dynamism of Actin Enables Secretory Function in Cytolytic Cells. Current Biology 28, 489-502.e9.

Carroll-Portillo, A., Spendier, K., Pfeiffer, J., Griffiths, G., Li, H., Lidke, K.A., Oliver, J.M., Lidke, D.S., Thomas, J.L., Wilson, B.S., et al. (2010). Formation of a Mast Cell Synapse: Fc RI Membrane Dynamics upon Binding Mobile or Immobilized Ligands on Surfaces. The Journal of Immunology 184, 1328-1338.

Cazaux, S., Sadoun, A., Biarnes-Pelicot, M., Martinez, M., Obeid, S., Bongrand, P., Limozin, L., and Puech, P.-H. (2016). Synchronizing atomic force microscopy force mode and fluorescence microscopy in real time for immune cell stimulation and activation studies. Ultramicroscopy $160,168-181$.

Chang, V.T., Fernandes, R.A., Ganzinger, K.A., Lee, S.F., Siebold, C., McColl, J., Jönsson, P., Palayret, M., Harlos, K., Coles, C.H., et al. (2016). Initiation of T cell signaling by CD45 segregation at "close contacts." Nature Immunology 17, 574-582.

Chen, B.-C., Legant, W.R., Wang, K., Shao, L., Milkie, D.E., Davidson, M.W., Janetopoulos, C., Wu, X.S., Hammer, J.A., Liu, Z., et al. (2014). Lattice light-sheet microscopy: Imaging molecules to embryos at high spatiotemporal resolution. Science 346, 1257998.

Chiossone, L., Dumas, P.-Y., Vienne, M., and Vivier, E. (2018). Natural killer cells and other innate lymphoid cells in cancer. Nature Reviews Immunology 18, 671-688.

Chouaki-Benmansour, N., Ruminski, K., Sartre, A.-M., Phelipot, M.-C., Salles, A., Bergot, E., Wu, A., Chicanne, G., Fallet, M., Brustlein, S., et al. (2018). Phosphoinositides regulate the TCR/CD3 complex membrane dynamics and activation. Scientific Reports 8, 4966.

Choudhuri, K., Wiseman, D., Brown, M.H., Gould, K., and van der Merwe, P.A. (2005). T-cell receptor triggering is critically dependent on the dimensions of its peptide-MHC ligand. Nature 436, 578-582.

Colin-York, H., Javanmardi, Y., Skamrahl, M., Kumari, S., Chang, V.T., Khuon, S., Taylor, A., Chew, T.-L., Betzig, E., Moeendarbary, E., et al. (2019). Cytoskeletal Control of Antigen-Dependent T Cell Activation. Cell Reports 26, 3369-3379.e5.

Comrie, W.A., Babich, A., and Burkhardt, J.K. (2015). F-actin flow drives affinity maturation and spatial organization of LFA-1 at the immunological synapse. The Journal of Cell Biology 208, 475-491.

Cretel, E., Touchard, D., Bongrand, P., and Pierres, A. (2011). A new method for rapid detection of T lymphocyte decision to proliferate after encountering activating surfaces. Journal of Immunological Methods 364, 33-39.

Crites, T.J., Padhan, K., Muller, J., Krogsgaard, M., Gudla, P.R., Lockett, S.J., and Varma, R. (2014). TCR Microclusters Pre-Exist and Contain Molecules Necessary for TCR Signal Transduction. The Journal of Immunology 193, 56-67.

Das, D.K., Feng, Y., Mallis, R.J., Li, X., Keskin, D.B., Hussey, R.E., Brady, S.K., Wang, J.-H., Wagner, G., Reinherz, E.L., et al. (2015). Force-dependent transition in the T-cell receptor $\beta$-subunit allosterically regulates peptide discrimination and pMHC bond lifetime. Proceedings of the National Academy of Sciences 112, 1517-1522.

Delcassian, D., Depoil, D., Rudnicka, D., Liu, M., Davis, D.M., Dustin, M.L., and Dunlop, I.E. (2013). Nanoscale Ligand Spacing Influences Receptor Triggering in T Cells and NK Cells. Nano Letters 13, 5608-5614.

Delon, J., Kaibuchi, K., and Germain, R.N. (2001). Exclusion of CD43 from the Immunological Synapse Is Mediated by Phosphorylation-Regulated Relocation of the Cytoskeletal Adaptor Moesin. Immunity 15, 691-701.

Dillard, P., Varma, R., Sengupta, K., and Limozin, L. (2014). Ligand-Mediated Friction Determines Morphodynamics of Spreading T Cells. Biophysical Journal 107, 2629-2638.

Doh, J., and Irvine, D.J. (2006). Immunological synapse arrays: Patterned protein surfaces that modulate immunological synapse structure formation in T cells. Proceedings of the National Academy of Sciences 103, 5700-5705.

Dushek, O., Mueller, S., Soubies, S., Depoil, D., Caramalho, I., Coombs, D., and Valitutti, S. (2008). Effects of Intracellular Calcium and Actin Cytoskeleton on TCR Mobility Measured by Fluorescence Recovery. PLoS ONE 3, e3913.

Dustin, M.L. (2008a). T-cell activation through immunological synapses and kinapses. Immunological Reviews 221, 77-89.

Dustin, M.L. (2008b). Hunter to Gatherer and Back: Immunological Synapses and Kinapses as Variations on the Theme of Amoeboid Locomotion. Annual Review of Cell and Developmental Biology 24, 577-596. 
Dustin, M.L., and Groves, J.T. (2012). Receptor Signaling Clusters in the Immune Synapse. Annual Review of Biophysics 41, $543-$ 556.

Evans, E., Heinrich, V., Leung, A., and Kinoshita, K. (2005). Nano- to Microscale Dynamics of P-Selectin Detachment from Leukocyte Interfaces. I. Membrane Separation from the Cytoskeleton. Biophysical Journal 88, 2288-2298.

Fasting, C., Schalley, C.A., Weber, M., Seitz, O., Hecht, S., Koksch, B., Dernedde, J., Graf, C., Knapp, E.-W., and Haag, R. (2012). Multivalency as a Chemical Organization and Action Principle. Angewandte Chemie International Edition 51, 10472-10498.

Feng, Y., Brazin, K.N., Kobayashi, E., Mallis, R.J., Reinherz, E.L., and Lang, M.J. (2017). Mechanosensing drives acuity of $\alpha \beta$ T-cell recognition. Proceedings of the National Academy of Sciences 114, E8204-E8213.

Fenz, S.F., and Sengupta, K. (2012). Giant vesicles as cell models. Integrative Biology 4, 982.

Fenz, S.F., Bihr, T., Schmidt, D., Merkel, R., Seifert, U., Sengupta, K., and Smith, A.-S. (2017). Membrane fluctuations mediate lateral interaction between cadherin bonds. Nature Physics 13, 906-913.

Franz, C.M., and Puech, P.-H. (2008). Atomic Force Microscopy: A Versatile Tool for Studying Cell Morphology, Adhesion and Mechanics. Cellular and Molecular Bioengineering 1, 289-300.

Freeman, S.A., Goyette, J., Furuya, W., Woods, E.C., Bertozzi, C.R., Bergmeier, W., Hinz, B., van der Merwe, P.A., Das, R., and Grinstein, S. (2016). Integrins Form an Expanding Diffusional Barrier that Coordinates Phagocytosis. Cell 164, 128-140.

Freeman, S.A., Vega, A., Riedl, M., Collins, R.F., Ostrowski, P.P., Woods, E.C., Bertozzi, C.R., Tammi, M.I., Lidke, D.S., Johnson, P., et al. (2018). Transmembrane Pickets Connect Cyto- and Pericellular Skeletons Forming Barriers to Receptor Engagement. Cell 172, 305-317.e10.

Gakamsky, D.M., Luescher, I.F., Pramanik, A., Kopito, R.B., Lemonnier, F., Vogel, H., Rigler, R., and Pecht, I. (2005). CD8 Kinetically Promotes Ligand Binding to the T-Cell Antigen Receptor. Biophysical Journal 89, 2121-2133.

Gaus, K., Chklovskaia, E., Fazekas de St. Groth, B., Jessup, W., and Harder, T. (2005). Condensation of the plasma membrane at the site of T lymphocyte activation. The Journal of Cell Biology 171, 121-131.

Getahun, A., and Cambier, J.C. (2015). Of ITIMs, ITAMs, and ITAMis: revisiting immunoglobulin Fc receptor signaling. Immunological Reviews 268, 66-73.

González, C., Chames, P., Kerfelec, B., Baty, D., Robert, P., and Limozin, L. (2019). Nanobody-CD16 Catch Bond Reveals NK Cell Mechanosensitivity. Biophysical Journal 116, 1516-1526.

Grakoui, A., Bromley, S.K., Sumen, C., Davis, M.M., Shaw, A.S., Allen, P.M., and Dustin, M.L. (1999). The immunological synap se: a molecular machine controlling T cell activation. Science 285, 221-227.

Guia, S., Jaeger, B.N., Piatek, S., Mailfert, S., Trombik, T., Fenis, A., Chevrier, N., Walzer, T., Kerdiles, Y.M., Marguet, D., et al. (2011). Confinement of Activating Receptors at the Plasma Membrane Controls Natural Killer Cell Tolerance. Science Signaling $4, \mathrm{ra} 21$.

Hartman, N.C., Nye, J.A., and Groves, J.T. (2009). Cluster size regulates protein sorting in the immunological synapse. Proceedings of the National Academy of Sciences 106, 12729-12734.

Hashimoto-Tane, A., Sakuma, M., Ike, H., Yokosuka, T., Kimura, Y., Ohara, O., and Saito, T. (2016). Micro-adhesion rings surrounding TCR microclusters are essential for T cell activation. The Journal of Experimental Medicine 213, 1609-1625.

He, H.-T., and Bongrand, P. (2012). Membrane dynamics shape TCR-generated signaling. Frontiers in Immunology 3, 90.

Heinrich, V. (2015). Controlled One-on-One Encounters between Immune Cells and Microbes Reveal Mechanisms of Phagocytosis. Biophysical Journal 109, 469-476.

Herant, M., Lee, C.-Y., Dembo, M., and Heinrich, V. (2011). Protrusive Push versus Enveloping Embrace: Computational Model of Phagocytosis Predicts Key Regulatory Role of Cytoskeletal Membrane Anchors. PLoS Computational Biology 7, e1001068.

Hivroz, C., and Saitakis, M. (2016). Biophysical Aspects of T Lymphocyte Activation at the Immune Synapse. Frontiers in Immunology 7, 46 .

Hoffmann, S., Hosseini, B.H., Hecker, M., Louban, I., Bulbuc, N., Garbi, N., Wabnitz, G.H., Samstag, Y., Spatz, J.P., and Hämmerling, G.J. (2011). Single cell force spectroscopy of T cells recognizing a myelin-derived peptide on antigen presenting cells. Immunology Letters 136, 13-20.

Hong, J., Ge, C., Jothikumar, P., Yuan, Z., Liu, B., Bai, K., Li, K., Rittase, W., Shinzawa, M., Zhang, Y., et al. (2018). A TCR mechanotransduction signaling loop induces negative selection in the thymus. Nature Immunology 19, 1379-1390.

Hu, K.H., and Butte, M.J. (2016). T cell activation requires force generation. The Journal of Cell Biology 213, 535-542.

Huang, J., Zarnitsyna, V.I., Liu, B., Edwards, L.J., Jiang, N., Evavold, B.D., and Zhu, C. (2010). The kinetics of two-dimensional TCR and pMHC interactions determine T-cell responsiveness. Nature 464, 932-936.

Huang, W.Y.C., Alvarez, S., Kondo, Y., Lee, Y.K., Chung, J.K., Lam, H.Y.M., Biswas, K.H., Kuriyan, J., and Groves, J.T. (2019). A molecular assembly phase transition and kinetic proofreading modulate Ras activation by SOS. Science 363, 1098-1103.

Hui, E., and Vale, R.D. (2014). In vitro membrane reconstitution of the T-cell receptor proximal signaling network. Nature Structural \& Molecular Biology 21, 133-142.

Huppa, J.B., Axmann, M., Mörtelmaier, M.A., Lillemeier, B.F., Newell, E.W., Brameshuber, M., Klein, L.O., Schütz, G.J., and Davis, M.M. (2010). TCR-peptide-MHC interactions in situ show accelerated kinetics and increased affinity. Nature 463, $963-967$.

Husson, J., Chemin, K., Bohineust, A., Hivroz, C., and Henry, N. (2011). Force Generation upon T Cell Receptor Engagement. PLoS ONE 6, e19680.

James, J.R., and Vale, R.D. (2012). Biophysical mechanism of T-cell receptor triggering in a reconstituted system. Nature 487, 6469.

Jankowska, K.I., Williamson, E.K., Roy, N.H., Blumenthal, D., Chandra, V., Baumgart, T., and Burkhardt, J.K. (2018). Integrin s Modulate T Cell Receptor Signaling by Constraining Actin Flow at the Immunological Synapse. Frontiers in Immunology 9, 25.

Jung, Y., Riven, I., Feigelson, S.W., Kartvelishvily, E., Tohya, K., Miyasaka, M., Alon, R., and Haran, G. (2016). Three-dimensional localization of T-cell receptors in relation to microvilli using a combination of superresolution microscopies. Proceedings of the National Academy of Sciences 113, E5916-E5924.

Kim, S.T., Takeuchi, K., Sun, Z.-Y.J., Touma, M., Castro, C.E., Fahmy, A., Lang, M.J., Wagner, G., and Reinherz, E.L. (2009). The $\alpha \beta$ T Cell Receptor Is an Anisotropic Mechanosensor. Journal of Biological Chemistry 284, 31028-31037. 
Kinoshita, K., Leung, A., Simon, S., and Evans, E. (2010). Long-Lived, High-Strength States of ICAM-1 Bonds to $\beta 2$ Integrin, II: Lifetimes of LFA-1 Bonds Under Force in Leukocyte Signaling. Biophysical Journal 98, 1467-1475.

Köhler, K., Xiong, S., Brzostek, J., Mehrabi, M., Eissmann, P., Harrison, A., Cordoba, S.-P., Oddos, S., Miloserdov, V., Gould, K., et al. (2010). Matched Sizes of Activating and Inhibitory Receptor/Ligand Pairs Are Required for Optimal Signal Integration by Human Natural Killer Cells. PLoS ONE 5, e15374.

Krogsgaard, M., and Davis, M.M. (2005). How T cells "see" antigen. Nature Immunology 6, 239-245.

Kumari, S., Depoil, D., Martinelli, R., Judokusumo, E., Carmona, G., Gertler, F.B., Kam, L.C., Carman, C.V., Burkhardt, J.K., Irvine, D.J., et al. (2015). Actin foci facilitate activation of the phospholipase $\mathrm{C}-\gamma$ in primary T lymphocytes via the WASP pathway. ELife 4, e04953.

Lillemeier, B.F., Mörtelmaier, M.A., Forstner, M.B., Huppa, J.B., Groves, J.T., and Davis, M.M. (2010). TCR and Lat are expressed on separate protein islands on T cell membranes and concatenate during activation. Nature Immunology 11, 90-96.

Limozin, L., and Sengupta, K. (2009). Quantitative Reflection Interference Contrast Microscopy (RICM) in Soft Matter and Cell Adhesion. ChemPhysChem 10, 2752-2768.

Limozin, L., Bärmann, M., and Sackmann, E. (2003). On the organization of self-assembled actin networks in giant vesicles. The European Physical Journal E 10,319-330.

Limozin, L., Bongrand, P., and Robert, P. (2016). A Rough Energy Landscape to Describe Surface-Linked Antibody and Antigen Bond Formation. Scientific Reports 6,35193.

Limozin, L., Bridge, M., Bongrand, P., Dushek, O., Van Der Merwe, P.A., and Robert, P. (2019). TCR-pMHC kinetics under force in a cell-free system show no intrinsic catch bond, but a minimal encounter duration before binding. Accepted in Proceedings of the National Academy of Sciences.

Lin, J.J.Y., Low-Nam, S.T., Alfieri, K.N., McAffee, D.B., Fay, N.C., and Groves, J.T. (2019). Mapping the stochastic sequence of individual ligand-receptor binding events to cellular activation: T cells act on the rare events. Science Signaling 12, eaat8715.

Liu, B., Chen, W., Evavold, B.D., and Zhu, C. (2014). Accumulation of Dynamic Catch Bonds between TCR and Agonist PeptideMHC Triggers T Cell Signaling. Cell 157, 357-368.

Liu, C.S.C., Raychaudhuri, D., Paul, B., Chakrabarty, Y., Ghosh, A.R., Rahaman, O., Talukdar, A., and Ganguly, D. (2018). Cutting Edge: Piezo1 Mechanosensors Optimize Human T Cell Activation. The Journal of Immunology 200, 1255-1260.

Liu, W., Wang, H., and Xu, C. (2016a). Antigen Receptor Nanoclusters: Small Units with Big Functions. Trends in Immunology 37, 680-689.

Liu, Y., Blanchfield, L., Ma, V.P.-Y., Andargachew, R., Galior, K., Liu, Z., Evavold, B., and Salaita, K. (2016b). DNA-based nanoparticle tension sensors reveal that T-cell receptors transmit defined $\mathrm{pN}$ forces to their antigens for enhanced fidelity. Proceedings of the National Academy of Sciences 113, 5610-5615.

Lo Schiavo, V., Robert, P., Limozin, L., and Bongrand, P. (2012). Quantitative Modeling Assesses the Contribution of Bond Strengthening, Rebinding and Force Sharing to the Avidity of Biomolecule Interactions. PLoS ONE 7, e44070.

Ma, V.P.-Y., Liu, Y., Blanchfield, L., Su, H., Evavold, B.D., and Salaita, K. (2016). Ratiometric Tension Probes for Mapping Receptor Forces and Clustering at Intermembrane Junctions. Nano Letters 16, 4552-4559.

Malissen, B., and Bongrand, P. (2015). Early T Cell Activation: Integrating Biochemical, Structural, and Biophysical Cues. Annual Review of Immunology 33, 539-561.

Mammen, M., Choi, S.-K., and Whitesides, G.M. (1998). Polyvalent Interactions in Biological Systems: Implications for Design and Use of Multivalent Ligands and Inhibitors. Angewandte Chemie International Edition 37, 2754-2794.

Manz, B.N., Jackson, B.L., Petit, R.S., Dustin, M.L., and Groves, J. (2011). T-cell triggering thresholds are modulated by the number of antigen within individual T-cell receptor clusters. Proceedings of the National Academy of Sciences 108, 9089-9094.

Masters, T.A., Pontes, B., Viasnoff, V., Li, Y., and Gauthier, N.C. (2013). Plasma membrane tension orchestrates membrane trafficking, cytoskeletal remodeling, and biochemical signaling during phagocytosis. Proceedings of the National Academy of Sciences 110, 11875-11880.

Matalon, O., Ben- Shmuel, A., Kivelevitz, J., Sabag, B., Fried, S., Joseph, N., Noy, E., Biber, G., and Barda- Saad, M. (2018). Actin retrograde flow controls natural killer cell response by regulating the conformation state of SHP- 1. The EMBO Journal 37 , e96264.

Mensali, N., Dillard, P., Hebeisen, M., Lorenz, S., Theodossiou, T., Myhre, M.R., Fåne, A., Gaudernack, G., Kvalheim, G., Myklebust, J.H., et al. (2019). NK cells specifically TCR-dressed to kill cancer cells. EBioMedicine 40, 106-117.

van der Merwe, P.A., and Dushek, O. (2011). Mechanisms for T cell receptor triggering. Nature Reviews Immunology 11, 47-55.

Mossman, K.D., Campi, G., Groves, J.T., and Dustin, M.L. (2005). Altered TCR Signaling from Geometrically Repatterned Immunological Synapses. Science 310, 1191-1193.

Murphy, K., and Weaver, C. (2016). Janeway’s Immunobiology (Garland Science).

Murugesan, S., Hong, J., Yi, J., Li, D., Beach, J.R., Shao, L., Meinhardt, J., Madison, G., Wu, X., Betzig, E., et al. (2016). Formingenerated actomyosin arcs propel $\mathrm{T}$ cell receptor microcluster movement at the immune synapse. The Journal of Cell Biology 215, 383-399.

Natkanski, E., Lee, W.-Y., Mistry, B., Casal, A., Molloy, J.E., and Tolar, P. (2013). B Cells Use Mechanical Energy to Discriminate Antigen Affinities. Science 340, 1587-1590.

Nordenfelt, P., Elliott, H.L., and Springer, T.A. (2016). Coordinated integrin activation by actin-dependent force during T-cell migration. Nature Communications 7, 13119.

Ostrowski, P.P., Grinstein, S., and Freeman, S.A. (2016). Diffusion Barriers, Mechanical Forces, and the Biophysics of Phagocytosis. Developmental Cell 38, 135-146.

Pageon, S.V., Tabarin, T., Yamamoto, Y., Ma, Y., Bridgeman, J.S., Cohnen, A., Benzing, C., Gao, Y., Crowther, M.D., Tungatt, K., et al. (2016). Functional role of T-cell receptor nanoclusters in signal initiation and antigen discrimination. Proceedings of the National Academy of Sciences 113, E5454-E5463.

Palmer, A.E., and Tsien, R.Y. (2006). Measuring calcium signaling using genetically targetable fluorescent indicators. Nature Protocols 1, 1057-1065. 
Pecht, I. (2018). Immuno-receptors: from recognition to signaling and function. European Biophysics Journal 47, 363-371.

Pettmann, J., Santos, A.M., Dushek, O., and Davis, S.J. (2018). Membrane Ultrastructure and T Cell Activation. Frontiers in Immunology 9, 2152.

Pi, F., Dillard, P., Limozin, L., Charrier, A., and Sengupta, K. (2013). Nanometric protein-patch arrays on glass and polydimethylsiloxane for cell adhesion studies. Nano Lett. 13, 3372-3378.

Pi, F., Dillard, P., Alameddine, R., Benard, E., Wahl, A., Ozerov, I., Charrier, A., Limozin, L., and Sengupta, K. (2015). Size-Tunable Organic Nanodot Arrays: A Versatile Platform for Manipulating and Imaging Cells. Nano Lett. 15, 5178-5184.

Pielak, R.M., O’Donoghue, G.P., Lin, J.J., Alfieri, K.N., Fay, N.C., Low-Nam, S.T., and Groves, J.T. (2017). Early T cell receptor signals globally modulate ligand:receptor affinities during antigen discrimination. Proceedings of the National Academy of Sciences $114,12190-12195$.

Pierobon, P., and Lennon-Duménil, A.-M. (2017). To use or not to use the force: How B lymphocytes extract surface-tethered antigens. The Journal of Cell Biology 216, 17-19.

Ponjavic, A., McColl, J., Carr, A.R., Santos, A.M., Kulenkampff, K., Lippert, A., Davis, S.J., Klenerman, D., and Lee, S.F. (2018). Single-Molecule Light-Sheet Imaging of Suspended T Cells. Biophysical Journal 114, 2200-2211.

Puech, P.-H., Feracci, H., and Brochard-Wyart, F. (2004). Adhesion between Giant Vesicles and Supported Bilayers Decorated with Chelated E-Cadherin Fragments. Langmuir 20,9763-9768.

Puech, P.-H., Nevoltris, D., Robert, P., Limozin, L., Boyer, C., and Bongrand, P. (2011). Force Measurements of TCR/pMHC Recognition at T Cell Surface. PLoS ONE 6, e22344.

Razvag, Y., Neve-Oz, Y., Sajman, J., Reches, M., and Sherman, E. (2018). Nanoscale kinetic segregation of TCR and CD45 in engaged microvilli facilitates early $\mathrm{T}$ cell activation. Nature Communications 9, 732.

Ritter, A.T., Asano, Y., Stinchcombe, J.C., Dieckmann, N.M.G., Chen, B.-C., Gawden-Bone, C., van Engelenburg, S., Legant, W., Gao, L., Davidson, M.W., et al. (2015). Actin Depletion Initiates Events Leading to Granule Secretion at the Immunological Synapse. Immunity 42, 864-876.

Robert, P., Nicolas, A., Aranda-Espinoza, S., Bongrand, P., and Limozin, L. (2011). Minimal Encounter Time and Separation Determine Ligand-Receptor Binding in Cell Adhesion. Biophysical Journal 100, 2642-2651.

Robert, P., Aleksic, M., Dushek, O., Cerundolo, V., Bongrand, P., and van der Merwe, P.A. (2012). Kinetics and Mechanics of TwoDimensional Interactions between T Cell Receptors and Different Activating Ligands. Biophysical Journal 102, $248-257$.

Rossboth, B., Arnold, A.M., Ta, H., Platzer, R., Kellner, F., Huppa, J.B., Brameshuber, M., Baumgart, F., and Schütz, G.J. (2018). TCRs are randomly distributed on the plasma membrane of resting antigen-experienced T cells. Nature Immunology 19, 821827.

Rossy, J., Laufer, J.M., and Legler, D.F. (2018). Role of Mechanotransduction and Tension in T Cell Function. Frontiers in Immunology 9, 2638.

Roybal, K.T., Rupp, L.J., Morsut, L., Walker, W.J., McNally, K.A., Park, J.S., and Lim, W.A. (2016). Precision Tumor Recognition by T Cells With Combinatorial Antigen-Sensing Circuits. Cell 164, 770-779.

Salles, A., Billaudeau, C., Sergé, A., Bernard, A.-M., Phélipot, M.-C., Bertaux, N., Fallet, M., Grenot, P., Marguet, D., He, H.-T., et al. (2013). Barcoding T Cell Calcium Response Diversity with Methods for Automated and Accurate Analysis of Cell Signals (MAAACS). PLoS Computational Biology 9, e1003245.

Santos, A.M., Ponjavic, A., Fritzsche, M., Fernandes, R.A., de la Serna, J.B., Wilcock, M.J., Schneider, F., Urbančič, I., McColl, J., Anzilotti, C., et al. (2018). Capturing resting T cells: the perils of PLL. Nature Immunology 19, 203-205.

Sawicka, A., Babataheri, A., Dogniaux, S., Barakat, A.I., Gonzalez-Rodriguez, D., Hivroz, C., and Husson, J. (2017). Micropipette force probe to quantify single-cell force generation: application to T-cell activation. Molecular Biology of the Cell 28, 32293239.

Schmid, E.M., Bakalar, M.H., Choudhuri, K., Weichsel, J., Ann, H.S., Geissler, P.L., Dustin, M.L., and Fletcher, D.A. (2016). Sizedependent protein segregation at membrane interfaces. Nature Physics 12, 704-711.

Schwesinger, F., Ros, R., Strunz, T., Anselmetti, D., Guntherodt, H.-J., Honegger, A., Jermutus, L., Tiefenauer, L., and Pluckthun, A. (2000). Unbinding forces of single antibody-antigen complexes correlate with their thermal dissociation rates. Proceedings of the National Academy of Sciences 97, 9972-9977.

Seifert, U. (2002). Dynamic strength of adhesion molecules: Role of rebinding and self-consistent rates. Europhysics Letters (EPL) $58,792-798$.

Shaw, A., Hoffecker, I.T., Smyrlaki, I., Rosa, J., Grevys, A., Bratlie, D., Sandlie, I., Michaelsen, T.E., Andersen, J.T., and Högberg, B. (2019). Binding to nanopatterned antigens is dominated by the spatial tolerance of antibodies. Nature Nanotechnology $14,184-$ 190.

Shelby, S.A., Holowka, D., Baird, B., and Veatch, S.L. (2013). Distinct Stages of Stimulated FceRI Receptor Clustering and Immobilization Are Identified through Superresolution Imaging. Biophysical Journal 105, 2343-2354.

Sibener, L.V., Fernandes, R.A., Kolawole, E.M., Carbone, C.B., Liu, F., McAffee, D., Birnbaum, M.E., Yang, X., Su, L.F., Yu, W., et al. (2018). Isolation of a Structural Mechanism for Uncoupling T Cell Receptor Signaling from Peptide-MHC Binding. Cell 174, 672-687.e27.

Spillane, K.M., and Tolar, P. (2017). B cell antigen extraction is regulated by physical properties of antigen-presenting cells. The Journal of Cell Biology 216, 217-230.

Spillane, K.M., and Tolar, P. (2018). Mechanics of antigen extraction in the B cell synapse. Molecular Immunology 101, 319-328.

Springer, T.A., and Dustin, M.L. (2012). Integrin inside-out signaling and the immunological synapse. Current Opinion in Cell Biology 24, 107-115.

Stone, M.B., Shelby, S.A., Núñez, M.F., Wisser, K., and Veatch, S.L. (2017). Protein sorting by lipid phase-like domains supports emergent signaling function in B lymphocyte plasma membranes. ELife 6, e19891.

Su, X., Ditlev, J.A., Hui, E., Xing, W., Banjade, S., Okrut, J., King, D.S., Taunton, J., Rosen, M.K., and Vale, R.D. (2016). Phase separation of signaling molecules promotes T cell receptor signal transduction. Science 352, 595-599. 
Taylor, M.J., Husain, K., Gartner, Z.J., Mayor, S., and Vale, R.D. (2017). A DNA-Based T Cell Receptor Reveals a Role for Receptor Clustering in Ligand Discrimination. Cell 169, 108-119.e20.

Tolar, P. (2017). Cytoskeletal control of B cell responses to antigens. Nature Reviews Immunology 17, 621-634.

Treanor, B., Depoil, D., Gonzalez-Granja, A., Barral, P., Weber, M., Dushek, O., Bruckbauer, A., and Batista, F.D. (2010). The Membrane Skeleton Controls Diffusion Dynamics and Signaling through the B Cell Receptor. Immunity 32, 187-199.

Übelhart, R., Hug, E., Bach, M.P., Wossning, T., Dühren-von Minden, M., Horn, A.H.C., Tsiantoulas, D., Kometani, K., Kurosaki, T., Binder, C.J., et al. (2015). Responsiveness of B cells is regulated by the hinge region of IgD. Nature Immunology 16, 534-543.

Valitutti, S. (1995). Sustained signaling leading to T cell activation results from prolonged T cell receptor occupancy. Role of T cell actin cytoskeleton. Journal of Experimental Medicine 181, 577-584.

Valitutti, S., Müller, S., Cella, M., Padovan, E., and Lanzavecchia, A. (1995). Serial triggering of many T-cell receptors by a few peptide-MHC complexes. Nature 375, 148-151.

Varma, R., Campi, G., Yokosuka, T., Saito, T., and Dustin, M.L. (2006). T Cell Receptor-Proximal Signals Are Sustained in Peripheral Microclusters and Terminated in the Central Supramolecular Activation Cluster. Immunity 25, 117-127.

Vivier, E. (2004). Natural Killer Cell Signaling Pathways. Science 306, 1517-1519.

Vivier, E., Raulet, D.H., Moretta, A., Caligiuri, M.A., Zitvogel, L., Lanier, L.L., Yokoyama, W.M., and Ugolini, S. (2011). Innate or Adaptive Immunity? The Example of Natural Killer Cells. Science 331, 44-49.

Volkmann, C., Brings, N., Becker, M., Hobeika, E., Yang, J., and Reth, M. (2016). Molecular requirements of the B- cell antigen receptor for sensing monovalent antigens. The EMBO Journal 35, 2371-2381.

Wahl, A., Dinet, C., Dillard, P., Nassereddine, A., Puech, P.-H., Limozin, L., and Sengupta, K. (2019). Biphasic mechanosensitivity of T cell receptor-mediated spreading of lymphocytes. Proceedings of the National Academy of Sciences 116, 5908-5913.

Wan, Z., Chen, X., Chen, H., Ji, Q., Chen, Y., Wang, J., Cao, Y., Wang, F., Lou, J., Tang, Z., et al. (2015). The activation of IgM- or isotype-switched IgG- and IgE-BCR exhibits distinct mechanical force sensitivity and threshold. ELife 4, e06925.

Wu, W., Shi, X., and Xu, C. (2016). Regulation of T cell signalling by membrane lipids. Nature Reviews Immunology 16, 690-701.

Xu, C., Gagnon, E., Call, M.E., Schnell, J.R., Schwieters, C.D., Carman, C.V., Chou, J.J., and Wucherpfennig, K.W. (2008). Regulation of T Cell Receptor Activation by Dynamic Membrane Binding of the CD $3 \varepsilon$ Cytoplasmic Tyrosine-Based Motif. Cell 135, 702-713.

Yang, J., and Reth, M. (2010). Oligomeric organization of the B-cell antigen receptor on resting cells. Nature 467, 465-469.

Yokosuka, T., and Saito, T. (2010). The Immunological Synapse, TCR Microclusters, and T Cell Activation. In Immunological Synapse, T. Saito, and F.D. Batista, eds. (Berlin, Heidelberg: Springer Berlin Heidelberg), pp. 81-107.

Zarnitsyna, V., and Zhu, C. (2012). T cell triggering: insights from 2D kinetics analysis of molecular interactions. Physical Biology 9 , 045005.

Zeng, Y., Yi, J., Wan, Z., Liu, K., Song, P., Chau, A., Wang, F., Chang, Z., Han, W., Zheng, W., et al. (2015). Substrate stiffness regulates B-cell activation, proliferation, class switch, and T-cell-independent antibody responses in vivo: Cellular immune response. European Journal of Immunology 45, 1621-1634. 